\title{
Connectedness of habitat fragments boosts conservation benefits for butterflies, but only in landscapes with little cropland
}

\author{
Urs G. Kormann • Christoph Scherber · Teja Tscharntke • Péter Batáry • \\ Verena Rösch
}

Received: 18 July 2018 / Accepted: 13 May 2019

(C) Springer Nature B.V. 2019

\begin{abstract}
Context Global change pressures (GCPs) imperil species and associated ecosystem functions, but studies investigating interactions of landscape-scale pressures remain scarce. Loss of species-rich habitat and agricultural expansion are major threats for biodiversity, but if or how these factors interactively determine community-level shifts and conservation outcomes remains unclear.
\end{abstract}

Electronic supplementary material The online version of this article (https://doi.org/10.1007/s10980-019-00835-6) contains supplementary material, which is available to authorized users.

\author{
U. G. Kormann $(\bowtie) \cdot$ C. Scherber · T. Tscharntke · \\ P. Batáry · V. Rösch \\ Agroecology, University of Goettingen, Göttingen, \\ Germany \\ e-mail: urs.kormann@bfh.ch \\ C. Scherber \\ e-mail: Christoph.Scherber@uni-muenster.de \\ T. Tscharntke \\ e-mail: ttschar@gwdg.de \\ P. Batáry \\ e-mail: pbatary@gmail.com \\ V. Rösch \\ e-mail: roesch@uni-landau.de

\section{U. G. Kormann} \\ Forest Biodiversity Research Network, Oregon State \\ University, Corvallis, USA
}

Objectives We tested whether matrix simplification (dominance of cropland) and reduced connectivity (i.e. landscape-scale habitat loss) either additively, synergistically or antagonistically cause community shifts in butterflies, a group of high conservation relevance.

Methods We surveyed butterflies on 30 small calcareous grassland fragments $(<1 \mathrm{ha})$ in Central Germany, representing independent gradients in grassland connectivity (an index combining grassland area and proximity), and matrix quality (landscape proportion of cropland). Using proportional odds logistic regression, we assessed whether connectivity and matrix quality interactively altered the distribution of Red List

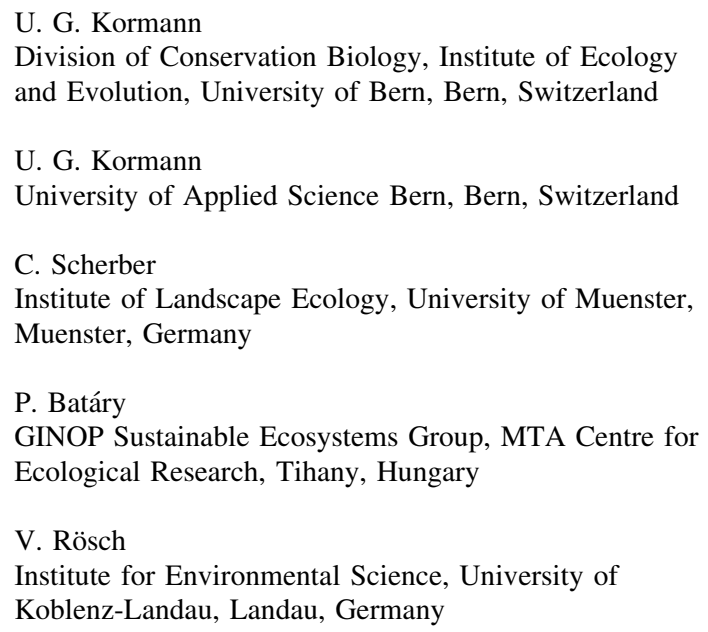


statuses, and assessed effects of local scale management (mowing, grazing, short-term abandonment).

Results We found synergistic, conservation relevant effects: Connectivity boosted the proportion of redlisted species from 20 to $52 \%$ in crop land poor landscapes, but not in crop land rich landscapes, particularly driven by endangered and critically endangered species. Grazed sites had the lowest species richness, abundance, and proportions of conservation relevant butterflies.

Implications Mitigation measures targeting one landscape-scale pressure only may be inefficient, particularly for red-listed species. Increasing habitat connectivity bolsters butterfly communities and potential pollination services, but only if accompanied by measures to soften the matrix. Hence, halting biodiversity losses needs better understanding and implementation of complex conservation measures at the landscape scale.

Keywords Calcareous grasslands - Habitat loss · Habitat fragmentation · Landscape composition · Redlisted species · Proportional odds logistic regression

\section{Introduction}

As humans continue to alter this planet, biodiversity is increasingly subjected to detrimental global change pressures (GCPs), such as climate change, invasive species, habitat loss or agricultural intensification (Sala et al. 2000). A growing body of scientific evidence now suggests that these pressures can not only act in isolation, but also amplify, or mitigate the effect of other pressures if they co-occur (Didham et al. 2007; Potts et al. 2010a; González-Varo et al. 2013; Scherber 2015). Three general types of scenarios are possible (Sala et al. 2000): First, the joint effect of two GCPs can equal the sum of the individual effects ("additive interaction hypothesis"). Second, the joint effect can be greater than the sum of the individual effects ("synergistic interaction hypothesis"). Climate change can for example exacerbate the effects of invasive species on native pollinators (Schweiger et al. 2010). Third, the joint effect can be less than the sum of the individual effects ("antagonistic interaction hypothesis"). For example, the negative responses to habitat loss have partly been compensated for by positive responses to climate warming in British butterflies (Warren et al. 2001). This has two important implications: First, it will be essential to describe for which GCPs such interactions exist and how exactly their joint effects manifest if we aim to conserve species and the services they provide. Second, understanding such interactions will require studies that are explicitly designed to test for interactive effects (Scherber 2015), either by experimental design or by statistical means, as joint effects may otherwise not be predicted correctly (Didham et al. 2007).

Previous work has made big strides to increase our understanding of the interaction of local with landscape scale pressures (Didham et al. 2007; GonzálezVaro et al. 2013). However, comparatively few studies were explicitly designed to investigate interactions of different landscape-scale pressures (Tscharntke et al. 2012; González-Varo et al. 2013). This is surprising, as landscape-scale global change pressures are thought to be particularly important in anthropogenically fragmented landscapes where populations of native species are increasingly restricted to networks of small habitat remnants (Tscharntke et al. 2012). Important local and landscape GCPs that affect fragmented populations include:

1. Reduced habitat connectivity (also known as habitat isolation, Brückmann et al. 2010; Kormann et al. 2015). Patches surrounded by fewer and smaller neighbors have reduced immigration rates (Hanski and Ovaskainen 2000; Schtickzelle et al. 2006), which increases extinction probability.

2. Altered matrix quality. Changes in land use between the patches, can influence communities in several ways, for example by altering movement between habitat patches (Fernandez-Chacon et al. 2014). Loos et al. (2015) showed, for example, that inter-patch movement of grassland specialist butterflies is reduced by intervening intensive agriculture. Further, some matrix types may provide resources for generalist, but not for specialist species (Steffan-Dewenter and Tscharntke 2000; Öckinger et al. 2011).

3. Local habitat deterioration. For many species, altered habitat quality within patches, e.g. through changes in management, can alter vegetation structure and composition and thus reduces the 
availability and quality of food and nesting resources (Thomas 1991; Öckinger et al. 2006; Kormann et al. 2015).

Calcareous grasslands have become a highly fragmented habitat type in Central Europe through losses due to the spread of industrial agriculture of approx. 90\% of their original extent (Poschlod and WallisDeVries 2002; Krauss et al. 2010). They still harbor extraordinarily diverse assemblages of specialized plants and invertebrates (van Swaay 2002). In particular, $48 \%$ of the 576 butterfly species native to Europe occur on calcareous grasslands, many of them now red-listed (Van Swaay 2002; van Swaay et al. 2002). In some regions of Central Europe up to $30 \%$ of its original species have already been lost (Filz et al. 2013). Nowadays, the scattered and isolated grassland remnants are frequently surrounded by a matrix of intensive agriculture (Kormann et al. 2015). Current conservation efforts primarily focus on local habitat management (Kormann et al. 2015). As traditional rotational shepherding has nowadays become uncommon in many regions, the remnants are often kept open by grazing by cattle or horses, late season mowing or shrub removal with intermittent abandonment. Contrastingly, landscape-level conservation approaches are rarely implemented (Zulka et al. 2013).

Most existing studies on butterflies have focused on sweeping measures such as species richness and total abundance (Krauss et al. 2003, 2010; Brückmann 2010; Öckinger et al. 2010, 2011). While certainly of value, those community-level properties may be poor indicators of species-level dynamics, particularly for conservation relevant species, perhaps due to strong compensatory dynamics maintaining communitylevel properties (Ås 1999; Supp and Ernest 2014). In particular, studies are scarce that evaluate interactive effects of multiple global change pressures on conservation-relevant (red-listed) species, limiting our ability to inform pollinator conservation policies.

Here, we set up a landscape scale study along two orthogonal gradients in habitat connectivity and matrix quality. This allowed us to explicitly investigate whether or not these two global change pressures interactively cause pollinator community shifts in a fragmented, highly conservation relevant habitat type. We investigated changes in butterfly community composition on small $(<1 \mathrm{ha})$ calcareous grassland remnants, which are representative for about $70 \%$ of all fragments in the study region (Southern Lower Saxony, Central Germany) (Kormann et al. 2015).

Through the use of ordered logistic regression we tested three alternative hypotheses on how connectivity and matrix quality cause conservation priority shifts: (1) Those two pressures act in an additive manner (no interaction; "additive GCP hypothesis"), (2) the two pressures amplify their detrimental effect (positive interaction; "GCP synergism hypothesis") or (3) they mitigate their negative effect on butterfly communities (negative interaction; "GCP antagonism hypothesis") (Sala et al. 2000). The difference between these three hypotheses is expected to become apparent when looking at the community shift observed between connected grasslands within a high-quality matrix (low share of arable land), compared to unconnected grasslands surrounded by a lowquality matrix (high share of arable land): Under the additive GCP hypothesis, the shift towards species of conservation concern should equal the shift from connected to unconnected grasslands plus the shift from low quality matrix grasslands to high quality matrix grasslands. In contrast, the observed shift should be stronger than the additive shift under the GCP synergism hypothesis, and lower than the additive shift if the GCP antagonism hypothesis applies.

\section{Methods}

Study area

The study was conducted in Southern Lower Saxony (Central Germany) in the districts Göttingen and Northeim $\left(51.5^{\circ} \mathrm{N}, 9.9^{\circ} \mathrm{E}\right.$, see Map S1 in (Kormann et al. 2015). The predominant crops grown in the area are cereals, maize and oilseed rape, interspersed with frequently mown, fertile meadows. Semi-natural habitats present in the landscape are forests and remaining small fragments of calcareous grassland. The latter belongs to the plant association Mesobrometum erecti Koch (1926), (Ellenberg and Leuschner 2010). Currently, there are two management strategies for these grasslands, grazing or mowing, but many of them are abandoned (management cessation). Grazing starts in mid-June at the earliest. Local livestock includes goats, sheep, horses/ponies and cattle. The stocking rate is often too high and/or 
the timespan the livestock spends on a fragment is too long in terms of livestock unit per hectare per time, resulting in trampling and the removal of almost all the biomass. Mowing typically takes place once every year from late summer to winter to ensure that plant seeds can ripen. On the fragments that we classified as abandoned, no management actions had taken place in the last 5-15 years. Fragments that had been abandoned $>15$ years were excluded from the study since without management the characteristic plant species assemblage gradually disappears.

Study design

Site selection was performed based on vectorized land-use classification maps (ATKIS-DLM 25/1 Landesvermessung und Geobasisinformationen Niedersachsen 1991-1996, Hanover, Germany) with the geographical information system ArcGis (ESRI Geoinformatik GmbH, Hannover, Germany) followed by field surveys in the study area. For a set of approximately 70 small sites $(<1$ ha) we then classified management as either mown, grazed or abandoned. Of those sites, we finally selected 30 small fragments of calcareous grassland (0.045-0.69 ha, mean $=0.3 \mathrm{ha})$ along two orthogonal gradients (Fig. 1): (1) A matrix quality gradient, i.e. an increasing percentage of arable land within a radius of $1000 \mathrm{~m}$ around the fragments $(9-78 \%$, mean $=$ 44\%). (2) A habitat connectivity gradient, measured by a connectivity index (CI) as described in Hanski and Ovaskainen (2000):

$\mathrm{CI}_{\mathrm{i}}=\Sigma \exp \left(-\alpha \mathrm{d}_{\mathrm{ij}}\right) \mathrm{A}_{\mathrm{j}}^{\beta}$

$A_{j}$ is the area of the neighboring fragment $j$ (in $\mathrm{m}^{2}$ ) and $\mathrm{d}_{\mathrm{ij}}$ is the edge-to-edge distance (in $\mathrm{m}$ ) from the focal fragment $i$ to the neighboring fragment $j . \alpha$ is a species-specific parameter describing a species' dispersal ability and $\beta$ is a parameter that describes the scaling of immigration. Since we applied the connectivity index to an entire community with several taxa, both scaling parameters $\alpha$ and $\beta$ were set to the commonly used value of 0.5 (e.g. Brückmann et al. 2010). Connectivity ranged between 0 and 443 (mean $=121)$ with larger values of the connectivity index indicating higher levels of connectivity. Only fragments with the occurrence of more than five characteristic calcareous grassland plant species were included in the study (Krauss et al. 2003).

The two explanatory variables habitat connectivity and matrix quality were not significantly correlated (Pearson correlation, $\mathrm{r}=-0.19, \mathrm{t}=-1.05$, d.f. $=28, p=0.303$, Fig. S2).
Fig. 1 The study design illustrated with digitized maps from our study region. Grasslands were selected to represent two independent gradients in grassland connectivity (left to right), and matrix quality (lower to higher row)

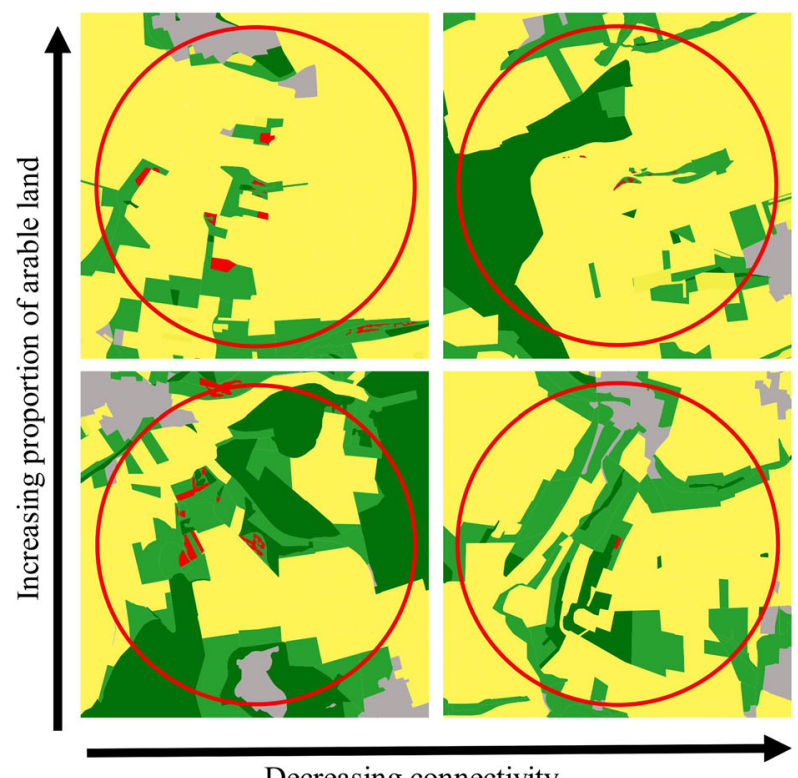

Decreasing connectivity
0

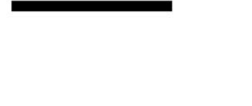

Legend

Calcareous grassland

Arable land

Settlement

Forest

Intensive grassland

Buffer $(r=1000 \mathrm{~m})$ 
Sampling methods

We sampled butterflies and burnet moths (Lepidoptera: Hesperioidea, Papilionidea and Zygaenidae) during standardized visual transect walks (Pollard 1977). Grasslands were visited four times between mid-May and early September 2011 during weather conditions suitable for butterfly sampling (temperature $>18{ }^{\circ} \mathrm{C}$, wind speed $<$ 4 Beaufort (approx. $30 \mathrm{~km} / \mathrm{h},<50 \%$ cloud cover, 10:00-17:30). On each grassland, we sampled butterflies with a hand net in transects $(5 \mathrm{~m}$ width and $180 \mathrm{~m}$ length). Transects were divided into three $60-\mathrm{m}$ segments, and we spent 4 min for surveying each segment, totaling 12 min per grassland and survey round. Butterflies were identified and released immediately afterwards. 27 butterfly individuals belonged to one of two species complexes (Aricia spp., $\mathrm{n}=26$; Leptidea spp., $\mathrm{n}=1$ ), which were not identifiable to species level in the field. For the calculation of species richness, these butterflies were treated as one species each (Aricia spp., Leptidea spp. respectively). However, given their uncertain Red List status, these individuals were excluded from the multinomial analysis.

\section{Specification of species characteristics}

Each butterfly species was assigned a Red List status according to the regional Red List (State of Lower Saxony, Lobenstein 2004):Critically endangered (CR), Endangered (EN), Vulnerable (VU), Near Threatened (NT), Least concern (LC). Furthermore, based on the host plant requirements of their larvae or climatic preferences they were classified as habitat specialists or generalists following Krauss et al. (2003). Red List status and habitat specialization were strongly correlated (Pearson correlation, $r=-0.67$, $\mathrm{t}=-6.07$, d.f. $=44, \mathrm{p}=<0.001$, coding of Red List status: Critically endangered $\mathrm{CR}=1$, Endangered $\mathrm{EN}=2$, Vulnerable $\mathrm{VU}=3$, Near Threatened NT $=$ 4, Least concern $\mathrm{LC}=5$ ). A species list with the respective characteristics can be found in Table S1.

\section{Statistical analyses}

We first analyzed shifts in the Red List status of butterfly communities in response to matrix quality, grassland connectivity and management type. For this, we fitted ordered multinomial logistic models, (proportional odds logistic regressions) to the Red List status of the observed butterflies (function polr in $\mathrm{R}$ package MASS) (Venables and Ripley 2002). This method can be seen as a logistic regression, but extended to model an ordered response variable with multiple categories (e.g. the Red List category of a species). The advantage of this approach is it allows to simultaneously model shifts in the proportion of different response categories (Red List categories) in one joint analysis. It therefore circumvents caveats regarding multiple testing that are associated with running multiple linear models for each response category. We started with the following explanatory variables: (1) habitat management (abandonment, grazing or mowing), (2) habitat connectivity (Hanski and Ovaskainen 2000), (3) matrix quality and (4) the interaction of habitat connectivity and matrix quality. We performed model simplification based on AICc (Akaike's information criterion for small sample sizes) using an automated stepwise selection procedure (function stepAICc URL: www.christophscherber.de/stepAICc.txt). We used a strong, conservative penalty term $(\mathrm{k}=\log (\mathrm{N})$; where $\mathrm{N}$ is the sample size) to identify those explanatory variables that had sufficient support by the data. For all models, connectivity and matrix quality were scaled prior to the analysis by subtracting the mean and by dividing by the standard deviation of the respective variable.

Species richness and abundance of butterflies per grassland fragment were analyzed using generalized linear models with Poisson or negative binomial error distribution (glm.nb or glm, R package MASS (Venables and Ripley 2002)), depending on the residual deviance. Management types were compared using the function glht in R package multcomp (Hothorn et al. 2016). As response variables, we used the abundance and species richness of (i) all butterflies, (ii) nonthreatened and (iii) red-listed butterflies respectively. The explanatory variables for the full models were the same as for the ordered multinomial logistic models. Similarly, we performed model simplification until AICc reached a local minimum, using $\mathrm{k}=2 \log (\mathrm{N})$ as the penalty term ( $\mathrm{N}$ is the sample size) Model assumptions were assessed using residual plots.

\section{Results}

In the 30 fragments of calcareous grassland we found 48 butterfly and burnet moth species (Lepidoptera: 
Hesperiidae, Papilionidae and Zygaenidae) (Table S1), from 30 genera with 2553 individuals (with 810, 594 and 1149 specimens caught on abandoned, grazed and mown sites, respectively), representing $22 \%$ of the German butterfly fauna (Binot-Hafke et al. 2011). Species richness ranged from 5 to 30 species per fragment. Of the 48 species that were recorded, 26 were red-listed (Lobenstein 2004). 1499 individuals (58.7\% of total abundance) belonged to non-threatened (least concern) species and 1054 individuals belonged to red-listed species (41.3\%). The most abundant non-threatened species were Maniola jurtina (302 individuals, $11.8 \%$ of total abundance), Pieris rapae (203 individuals, 8\%) and Melanargia galathea (177 individuals, 6.9\%). The most abundant red-listed species were Polyommatus coridon (EN, 654 individuals, 25.6\%), Argynnis aglaja (EN, 62 individuals, 2.4\%) and Melitaea aurelia (CR, 59 individuals, 2.3\%) (Table S1).

Multinomial model results indicated that matrix quality and habitat connectivity strongly determined the threat status of butterflies in the studied grasslands (Table 1; Fig. 2). Most importantly, a significant interaction between landscape quality and connectivity showed that butterfly communities increasingly shifted towards red-listed species when fragments were connected, but only in landscape with a high matrix quality and not in landscapes with low matrix quality, i.e. only in fragments that were surrounded by a low proportion of arable land (Table 1; Fig. 2). Further, management had a weak, although significant effect on the distribution of red-listed status (Table 1). While abandoned and grazed grasslands showed a similar distributions, mown grasslands had a slightly

Table 1 Summary table of the proportional odds logistic regression model testing the interactive effect of connectivity and matrix quality on the distribution of Red List statuses within the butterfly community

\begin{tabular}{llll}
\hline Explanatory variable & LR Chisq & Df & $\mathrm{p}$ \\
\hline Matrix quality & 121.156 & 1 & $<0.001$ \\
Connectivity & 29.903 & 1 & $<0.001$ \\
Management & 14.21 & 2 & 0.001 \\
Matrix quality $\times$ connectivity & 20.924 & 1 & $<0.001$ \\
\hline
\end{tabular}

Shown is the type-II analysis-of-variance table from likelihood-ratio tests lower fraction of red-listed species compared to abandoned and grazed grassland fragments (Fig. S1).

The generalized linear models did provide any support for an interaction of landscape quality and habitat connectivity when focusing on species richness and abundance (Table 2; Fig. 3). The best models rather indicated that increasing the proportion of arable land had a significantly negative effect on overall abundance $(p=0.004)$ and a marginally significant, negative effect on species richness $(\mathrm{p}=0.051)$. While overall abundance decreased by $67.2 \%$ (95\% CI [49.2; 78.9]) along the studied gradient in crop land cover, species richness declined by $37.5 \%$ (95\% CI $[17.3 ; 53.2])$. However, the best model did not indicate a connectivity effect on overall richness or abundance. When dividing species in nonthreatened and red-listed species, arable land negatively affected overall species richness and abundance of the red-listed butterflies $(\mathrm{p}=0.03$ and $<0.001$, respectively; Table 2; Fig. 3), but neither richness nor abundance of the non-threatened species butterflies. In addition, the only effect of habitat connectivity that was supported was a positive effect on species richness of red-listed species. Furthermore, grazing consistently reduced species richness for non-threatened, endangered and overall community respectively. However, only the abundance of the nonthreatened species was negatively affected by grazing, while the abundance of the red-listed species was not (Fig. 3; Table 2). Finally, we found statistically significant evidence that mown patches had the highest abundance of common species (Fig. 3; Table 2).

\section{Discussion}

By combining community-level analysis with an experimental design explicitly developed to investigate synergistic effects, we here show that landscapescale GCPs can synergistically cause conservationrelevant community shifts for butterflies in an endangered European grassland type. We found two key results: First, the lack of calcareous grasslands at the landscape scale negatively affected butterfly communities in our focal fragments, while this effect was amplified in landscapes dominated by agriculture. In particular, habitat connectivity had no significant positive effect on the proportion of red-listed species in the most agriculturally dominated landscapes, 
Fig. 2 Butterfly communities increasingly consist of red-listed species in connected fragments, but only in landscapes with high matrix quality (little cropland), supporting the "global change pressure synergism hypothesis" for these two landscape-scale factors. The y-axis indicates the predicted proportion of butterfly species belonging to a certain Red List status. Note that for unconnected grasslands, red-listed species account for a higher community proportion in high (left panel) compared to low quality matrix grasslands (right panel). Shown are model predictions for a "high quality matrix"-landscape (10\% arable land) and a "low matrix quality"landscape (80\% arable land)

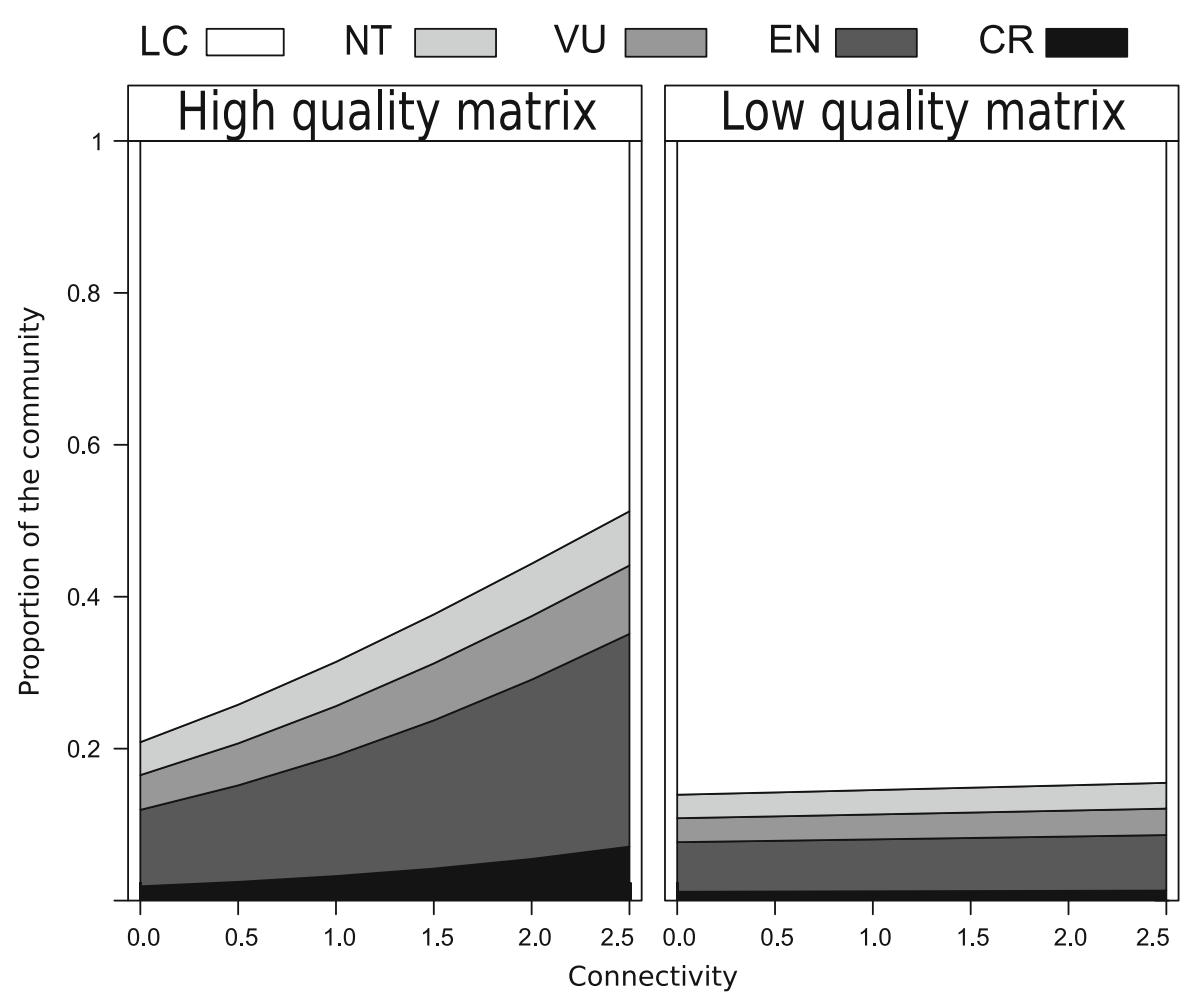

where they consistently accounted for less than $20 \%$ of the species. In contrast, increased connectivity caused a 2.5-fold increase in the proportion of red-listed butterflies on high-quality-matrix grasslands, i.e. from app. $20 \%$ on unconnected grasslands, to app. $50 \%$ on connected grasslands. Interestingly, this shift was driven by endangered or critically endangered species in particular. For example, the most isolated fragment surrounded by cropland harbored $0,1,0,2$ and 11 species of the Red List categories CR, EN, VU, NT and $\mathrm{LC}$, respectively, and was thus of relatively limited conservation value. In contrast, we found 2, 3, 2, 0 and 8 species belonging to those Red List categories on the most connected fragment surrounded by a high proportion of non-crop land, clearly indicating a site of high conservation value. Overall, this shows that a high quality matrix can intensify conservation benefits of landscape connectivity for butterflies. Thus, our results support the GCP synergistic interaction hypothesis for the effect of the two investigated landscape-scale pressures on the composition of the butterfly community.

Although our sampling effort with four observation rounds was similar to previously published studies (e.g. Sang et al. 2010, several datasets in Krauss et al.
2010), other studies had sampled considerably more (e.g. Brückmann et al. 2010). Despite this, we observed relatively large effect sizes across analyses (Figs. 2, 3; Tables 1, 2), which we interpret as strong evidence that sampling effort is sufficient to support our conclusions.

Importantly, the interactive effect of landscape connectivity and matrix quality was not apparent when focusing on butterfly abundance or species richness alone. Although these two metrics are widely used community descriptors in ecology and conservation biology, their suitability to assess biodiversity change has been criticized previously (Hillebrand et al. 2018; Kormann et al. 2018). Essentially, by focusing on richness and abundance only, we would wrongly have concluded that grassland isolation and matrix effects do not show interactive effects, even when nonthreatened and red-listed species were analyzed separately. Instead, by explicitly modelling the shift in Red List status across the landscape connectivitymatrix quality continuum, we showed that species of high conservation concern are particularly susceptible to interactive effects of global change pressures. 
Table 2 Generalized linear models on the effects of matrix quality (proportion arable land), habitat connectivity, and local management on abundance and species richness of common species, red-listed species and all species together
Significant variables $($ alpha $=0.05)$ are given in bold

Only the variables included in the final models are shown

\begin{tabular}{|c|c|c|c|c|c|}
\hline \multicolumn{2}{|l|}{ Common species } & \multirow{2}{*}{$\begin{array}{r}\text { Estimate } \\
2.280\end{array}$} & \multirow{2}{*}{$\frac{\text { SEM }}{0.100}$} & \multirow{2}{*}{$\frac{\text { z-value }}{22.590}$} & \multirow{2}{*}{$\frac{\mathrm{p}}{<\mathbf{0 . 0 0 1}}$} \\
\hline Species richness & Intercept & & & & \\
\hline & Management: grazing & -0.310 & 0.160 & -1.990 & $\mathbf{0 . 0 5 0}$ \\
\hline & Management: mown & 0.050 & 0.140 & 0.350 & 0.720 \\
\hline \multirow[t]{3}{*}{ Abundance } & Intercept & 3.840 & 0.120 & 32.840 & $<0.001$ \\
\hline & Management: grazing & -0.450 & 0.170 & -2.640 & 0.010 \\
\hline & Management: mown & 0.410 & 0.160 & 2.510 & 0.010 \\
\hline Red-listed species & & Estimate & SEM & z-value & $\mathrm{p}$ \\
\hline \multirow[t]{5}{*}{ Species richness } & Intercept & 1.690 & 0.180 & 9.290 & $<2 \mathrm{e}-16$ \\
\hline & Matrix quality & -0.250 & 0.120 & -2.160 & $\mathbf{0 . 0 3 0}$ \\
\hline & Connectivity & 0.240 & 0.120 & 1.930 & 0.050 \\
\hline & Management: grazing & -0.760 & 0.290 & -2.620 & 0.010 \\
\hline & Management: mown & 0.040 & 0.260 & 0.170 & 0.860 \\
\hline \multirow[t]{2}{*}{ Abundance } & Intercept & 3.430 & 0.200 & 17.040 & $<0.001$ \\
\hline & Matrix quality & -0.630 & 0.210 & $-\mathbf{3 . 0 7 0}$ & $<0.001$ \\
\hline All species & & Estimate & SEM & z-value & $\mathrm{p}$ \\
\hline \multirow[t]{4}{*}{ Species richness } & Intercept & 2.740 & 0.100 & 28.160 & $<0.001$ \\
\hline & Matrix quality & -0.120 & 0.060 & -1.960 & 0.049 \\
\hline & Management: grazing & -0.440 & 0.150 & -2.940 & $<0.001$ \\
\hline & Management: mown & 0.010 & 0.140 & 0.100 & 0.920 \\
\hline \multirow[t]{4}{*}{ Abundance } & Intercept & 4.440 & 0.160 & 27.490 & $<0.001$ \\
\hline & Matrix quality & -0.280 & 0.100 & -2.900 & $>0.001$ \\
\hline & Management: grazing & -0.440 & 0.230 & -1.920 & 0.050 \\
\hline & Management: mown & 0.240 & 0.230 & 1.030 & 0.300 \\
\hline
\end{tabular}

Connectivity and matrix quality

Both species richness and abundance of red-listed species decreased with decreasing matrix quality while their species richness increased with increasing connectivity. Irrespective of connectivity, patches embedded in low quality matrix had low proportions of red-listed butterflies. However, in landscapes with high matrix quality connectivity increased the proportion of red-listed butterflies in the community.

The intermediate landscape hypothesis predicts a lack of expected positive effects of local management extensification in highly simplified landscapes (Tscharntke et al. 2012). Similarly, we found increased connectivity to be little effective for boosting the proportion of red-listed butterflies in cleared landscapes. A likely reason for this is that cleared (low matrix quality) landscapes, compared to high quality matrix landscapes, did have a very depauperated species pool of common generalists (Figs. 2, 3) and thus simply lacked the capacity to respond to increased connectivity.

In today's agricultural landscapes, calcareous grasslands are among the last non-forest habitats that are not intensively managed (van Swaay et al. 2002), offering resources for both feeding and reproduction for numerous increasingly endangered butterfly species (Binot-Hafke et al. 2011). Many butterfly species persist in metapopulations, i.e. spatially structured grassland networks, characterized by local extinctions and subsequent recolonization events (Hanski 1998). While extinctions are often a result of local events, both recolonization and emigration under deteriorating local habitat conditions depend on connectivity as well as on the type of matrix surrounding each fragment (Kuussaari et al. 1996; Fernandez-Chacon et al. 2014). Our results thus support the idea that the matrix surrounding each fragment plays a crucial role in shaping butterfly communities in fragmented habitats (Kormann et al. 2015; Ernst et al. 2017). 


\section{Common Species species richness}
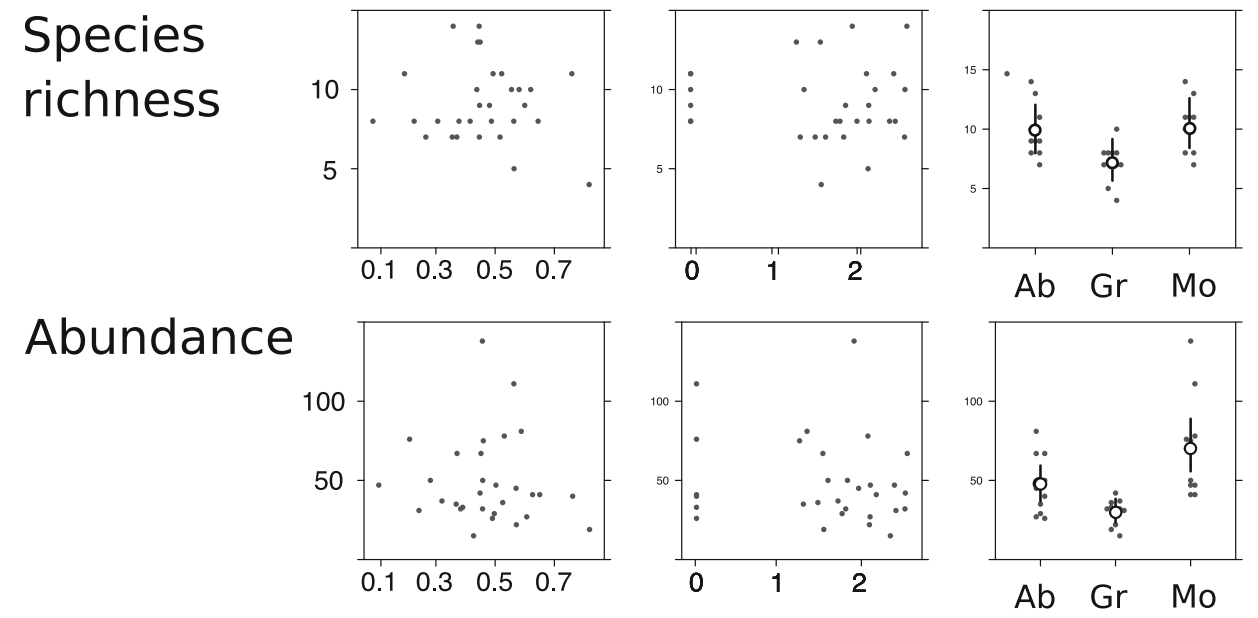

\section{Red listed species}

\section{Species richness}
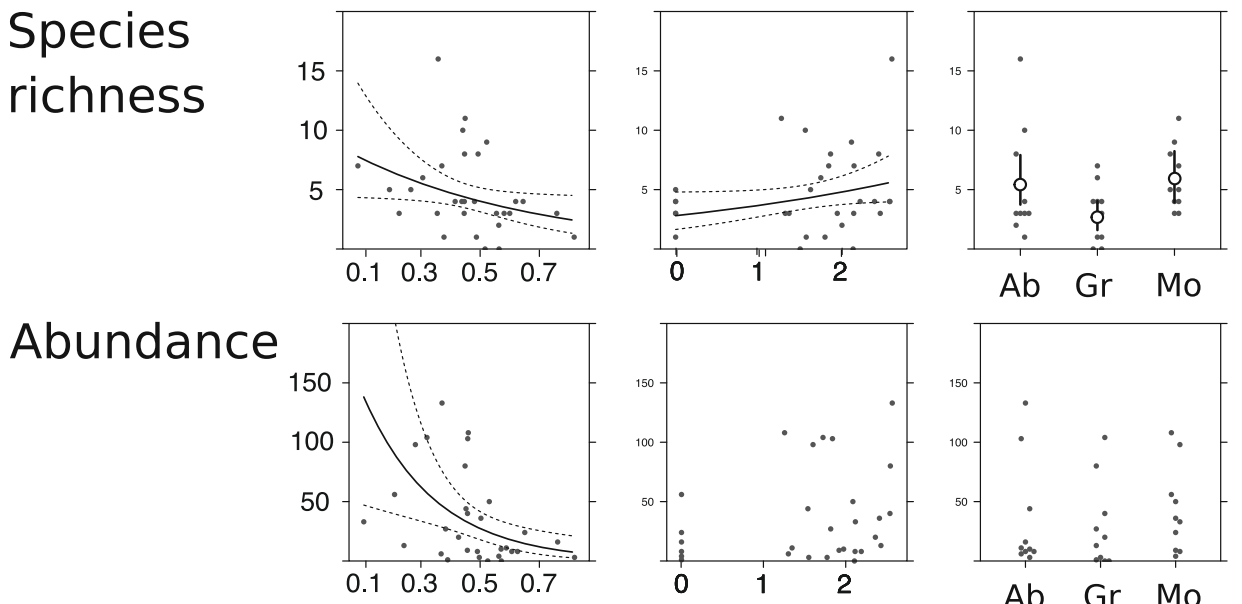

Matrix quality

Connectivity Management [prop.cropland]

Fig. 3 Species richness and abundance response of nonthreatened and red-listed butterflies to proportion of cropland, grassland connectivity, and local management. Shown are the raw data (dots) and predictions (solid lines and white circles)

Often, endangered species (i.e. species that have been assigned a Red List status), have more specific habitat requirements than non-endangered species (Ebert and Rennwald 1991). This pattern is also apparent in our data, where habitat specialists were more likely to be red-listed. In this study, grassland connectivity was only a significant driver of species richness for (the more specialized) red-listed species, but not for the common species. Thus, our results are in accordance with theoretical models that predict that specialists are more sensitive to habitat loss than generalist species (e.g. Steffan-Dewenter and Tscharntke 2000). Indeed, habitat specialist butterflies and their SE (dashed lines and whiskers) for significant effects. Connectivity is on a $\log 10(\mathrm{CI}+1)$-scale. $A b$ abandoned, $G r$ grazed, Mo mown

rely on plant species as larval food resources that are becoming increasingly rare (Garve 2004). In the study region and elsewhere, the occurrence of these plants is almost completely restricted to calcareous grasslands (Ernst et al. 2017), and suitable habitat patches for those butterflies are thus tightly delimited. On the contrary, larval food plants of generalist, non-threatened species are likely to be present in the landscape surrounding a fragment of calcareous grassland (e.g. nettle (Urtica dioica) and the small tortoiseshell Aglais urticae (Ebert and Rennwald 1991)). In this case the habitat fragment's boundaries are more diffuse, such that a countryside biogeography 
framework may more adequately describe species occurrence than classical meta-population models parametrized on calcareous grasslands alone.

Butterfly dispersal and habitat localization are not random processes but take place in a directed way and individuals are able to locate their preferred habitat at a considerable distance (Conradt et al. 2001). Both experimental and observational evidence is now accumulating that the matrix may modify butterfly dispersal in species-specific ways. Loos et al. (2015) documented with individual tracking surveys that most of the nine investigated species avoided arable land but favored the more heterogeneous parts of a given landscape. However, the degree to which agricultural land hampered movement differed greatly between species. In line with our study, FernandezChacon et al. (2014) found that similar patterns also manifest at the community level. In particular, these authors analyzed long-term butterfly extinction-colonization dynamics and showed that more permeable landscape types (natural vegetation, extensive cropland) increased colonization rates for most species. Additionally, Brückmann et al. (2010) found that species richness tended to be higher in connected sites, but failed to disentangle the effects of connectivity versus matrix quality. Overall, to our knowledge, our study is among the first ones to explicitly investigate interactive effects of matrix quality and connectivity at the butterfly community level, with a focus on redlisted species.

\section{Management}

Our results show that the type of management markedly influences both species richness and abundance as well as the composition of butterfly communities on small fragments of calcareous grassland. Recent studies have suggested that butterflies with specific habitat requirements (e.g. specialist butterflies) are more adapted to high quality sites, and may thus more strongly depend on local management aimed to counteract the local habitat degradation (but see Thomas 2016; Habel and Schmitt 2018 for details). In accordance, we found the proportionally strongest local management effect on the species richness of red-listed species (Table 2; Fig. 3).

Interestingly, our results suggest that common species were most abundant on mown communities, with roughly $50 \%$ and $100 \%$ more individuals compared to abandoned and grazed patches, respectively. Similarly, the multinomial model indicated that mown communities harbor the largest share of "Least Concern" species. In our study, grasslands were mostly mown in late summer or autumn, and thus provided ample floral resources during the flowering season. In general, however, lenient grazing is assumed to be the best management strategy for the maintenance of calcareous grasslands, since selective feeding of grazing livestock removes only part of the vegetation, leading to structural heterogeneity (Ausden et al. 2005). Also, grazing (typically by sheep) has been the main land-use form that has led to the creation of this grassland type (Poschlod and WallisDeVries 2002). However, this is in stark contrast with our findings, which suggest that grazing reduces butterfly abundances and species richness. The most likely explanation for this contradiction is that grazing of the small study grasslands was too intensive, resulting in a removal of most floral resources and larval food plants. Indeed, grazing often occurred over long periods of time and in some cases with high stocking rates of potentially unsuitable grazing animals such as cattle (personal observation). On the contrary, abandonment is clearly not a long-term solution since it will eventually lead to the loss of the typical grassland flora and fauna through a shift in plant community composition and subsequent shrub encroachment.

\section{Conclusions}

Our data add empirical support to the growing body of evidence that synergistic interaction effects of global change pressures negatively affect biotic communities. Management of butterflies on calcareous grasslands, i.e. of an ecologically important and culturally highly appreciated group on a high-value habitat type, should therefore focus on highly connected fragments surrounded by little agriculture. This further emphasizes that increasing habitat connectivity in agriculturally dominated landscapes will only promote butterfly conservation if accompanied by measures to soften the matrix. These findings are timely, since attempts of halting biodiversity losses need a better understanding and implementation of complex conservation measures on the landscape scale. 
Acknowledgements We thank three Reviewers and Adam Hadley for their input on a previous version of this article. Financial support to UGK by the DFG Research Training Group 1644 (Scaling Problems in Statistics), to PB by the German Research Foundation (Grant No. DFG BA4438/1-1) and to VR by the MWK graduate school "Biodiversität und Gesellschaft" is acknowledged. The Division of Conservation Biology, University of Bern, provided logistical support during the writing stage of this manuscript.

\section{References}

Ås S (1999) Invasion of matrix species in small habitat patches. Conserv Ecol 3:1

Ausden M, Hall M, Pearson P, Strudwick T (2005) The effects of cattle grazing on tall-herb fen vegetation and molluscs. Biol Conserv 122:317-326

Binot-Hafke, M., Balzer, S., Becker, N., Gruttke, H., Haupt, H., Hofbauer, N., Ludwig, G., Matzke-Hajek, G., \& Strauch, M. (2011) Rote Liste gefährdeter Tiere, Pflanzen und Pilze Deutschlands, Band 3: Wirbellose Tiere (Teil 1)

Brückmann SV (2010) Butterfly and plant specialists suffer from reduced connectivity in fragmented landscapes. J Appl Ecol 47:799-809

Brückmann SV, Krauss J, Steffan-Dewenter I (2010) Butterfly and plant specialists suffer from reduced connectivity in fragmented landscapes. J Appl Ecol 47:799-809

Conradt L, Roper TJ, Thomas CD (2001) Dispersal behaviour of individuals in metapopulations of two british butterflies. Oikos 95:416-424

Didham RK, Tylianakis JM, Gemmell NJ, Rand TA, Ewers RM (2007) Interactive effects of habitat modification and species invasion on native species decline. Trends Ecol Evolut 22:489-496

Ebert G, Rennwald E (1991) Die Schmetterlinge Baden-Württembergs. Ulmer, Stuttgart

Ellenberg H, Leuschner C (2010) Vegetation Mitteleuropas mit den Alpen in ökologischer, dynamischer und historischer Sicht. Ulmer, Stuttgart

Ernst LM, Tscharntke T, Batáry P (2017) Grassland management in agricultural vs. forested landscapes drives butterfly and bird diversity. Biol Conserv 216:51-59

Fernandez-Chacon A, Stefanescu C, Genovart M, Ferna A, Turco M, Oro D, Nichols JD, Hines JE, Pa F (2014) Determinants of extinction-colonization dynamics in Mediterranean butterflies: the role of landscape, climate and local habitat features. J Anim Ecol 83(1):276-285

Filz KJ, Engler JO, Stoffels J, Weitzel M, Schmitt T (2013) Missing the target? a critical view on butterfly conservation efforts on calcareous grasslands in south-western Germany. Biodivers Conserv 22:2223-2241

Garve E (2004) Rote Liste und Florenliste der Farn- und Blütenpflanzen in Niedersachsen und Bremen-5. Fassung, Stand 1.3. 2004. Informationsdienst Naturschutz Niedersachsen 1:1-76

González-Varo JP, Biesmeijer JC, Bommarco R, Potts SG, Schweiger O, Smith HG, Steffan-Dewenter I, Szentgyörgyi H, Woyciechowski M, Vilà M (2013) Combined effects of global change pressures on animal-mediated pollination. Trends Ecol Evol 28:524-530

Habel JC, Schmitt T (2018) Vanishing of the common species: empty habitats and the role of genetic diversity. Biol Conserv 218:211-216

Hanski I (1998) Metapopulation dynamics. Nature 396:41-49

Hanski I, Ovaskainen O (2000) The metapopulation capacity of a fragmented landscape. Nature 404:755-758

Hillebrand H, Blasius B, Borer ET, Chase JM, Stanley W, Downing JA, Klemens B, Christopher E, Seabloom EW, Hodapp D, Larsen S, Lewandowska AM, Van De Waal DB, Ryabov AB (2018) Biodiversity change is uncoupled from species richness trends: consequences for conservation and monitoring. J Appl Ecol 55(1):169-184

Hothorn T, Bretz F, Westfall P, Heiberger RM, Schuetzenmeister A, Scheibe S, Hothorn MT (2016) Package 'multcomp'. Simultaneous inference in general parametric models. Project for Statistical Computing, Vienna

Kormann U, Rösch V, Batáry P, Tscharntke T, Orci KM, Samu F, Scherber C (2015) Local and landscape management drive trait-mediated biodiversity of nine taxa on small grassland fragments. Divers Distrib 21:1204-1217

Kormann UG, Hadley AS, Tscharntke T, Betts MG, Robinson WD, Scherber C (2018) Primary rainforest amount at the landscape scale mitigates bird biodiversity loss and biotic homogenization. J Appl Ecol 55(3):1288-1298

Krauss J, Steffan-Dewenter I, Tscharntke T (2003) How does landscape context contribute to effects of habitat fragmentation on diversity and population density of butterflies? J Biogeogr 30:889-900

Krauss J, Bommarco R, Guardiola M, Heikkinen RK, Helm A, Kuussaari M, Lindborg R, Öckinger E, Pärtel M, Pino J, Pöyry J, Raatikainen KM, Sang A, Stefanescu C, Teder T, Zobel M, Steffan-Dewenter I (2010) Habitat fragmentation causes immediate and time-delayed biodiversity loss at different trophic levels. Ecol Lett 13:597-605

Kuussaari M, Nieminen M, Hanski I (1996) An experimental study of migration in the Glanville Fritillary butterfly, Melitea cinxia. J Appl Ecol 65:791-801

Lobenstein, U. (2004). Rote Liste der in Niedersachsen und Bremen gefährdeten Großschmetterlinge mit Gesamtartenverzeichnis: 2. Fassung, Stand 1.8. 2004. Nieders. Landesamt für Ökologie (NLÖ)-Abt. Naturschutz, 2004

Loos J, Kuussaari M, Ekroos J, Hanspach J, Fust P, Jackson L, Fischer J (2015) Changes in butterfly movements along a gradient of land use in farmlands of Transylvania (Romania). Landscape Ecol 30:625-635

Öckinger E, Eriksson AK, Smith HG (2006) Effects of grassland abandonment, restoration and management on butterflies and vascular plants. Biol Conserv 133:291-300

Öckinger E, Schweiger O, Crist TO, Debinski DM, Krauss J, Kuussaari M, Petersen JD, Pöyry J, Settele J, Summerville KS, Bommarco R (2010) Life-history traits predict species responses to habitat area and isolation: a cross-continental synthesis. Ecol Lett 13:969-979

Öckinger E, Bergman K-O, Franzén M, Kadlec T, Krauss J, Kuussaari M, Pöyry J, Smith HG, Steffan-Dewenter I, Bommarco R (2011) The landscape matrix modifies the effect of habitat fragmentation in grassland butterflies. Landscape Ecol 27:121-131 
Pollard E (1977) A method for assessing changes in the abundance of butterflies. Biol Conserv 12:115-134

Poschlod P, WallisDeVries MF (2002) The historical and socioeconomic perspective of calcareous grasslands-lessons from the distant and recent past. Biol Conserv 104:361-376

Potts SG, Biesmeijer JC, Kremen C, Neumann P, Schweiger O, Kunin WE (2010a) Global pollinator declines: trends, impacts and drivers. Trends Ecol Evol 25:345-353

Potts SG, Biesmeijer JC, Kremen C, Neumann P, Schweiger O, Kunin WE (2010b) Global pollinator declines: trends, impacts and drivers. Trends Ecol Evol 25:345-353

Sala OE, Iii FSC, Armesto JJ, Berlow E, Bloomfield J, Dirzo R, Huber-sanwald E, Huenneke LF, Jackson RB, Kinzig A, Leemans R, Lodge DM, Mooney HA, Poff NL, Sykes MT, Walker BH, Walker M (2000) Global biodiversity scenarios for the year 2100. Science 287:1770-1774

Sang A, Teder T, Helm A, Pärtel M (2010) Indirect evidence for an extinction debt of grassland butterflies half century after habitat loss. Biol Conserv 143(6):1405-1413

Scherber C (2015) Insect responses to interacting global change drivers in managed ecosystems. Curr Opin Insect Sci 11:56-62

Schtickzelle N, Mennechez G, Baguette M (2006) Dispersal depression with habitat fragmentation. Ecology 87:1057-1065

Schweiger O, Biesmeijer JC, Bommarco R, Hickler T, Hulme PE, Klotz S, Ingolf K, Moora M, Nielsen A, Ohlem R, Petanidou T, Potts SG, Py̌ P, Stout JC, Sykes MT, Tscheulin T, Winter M, Zobel M, Settele J (2010) Multiple stressors on biotic interactions: how climate change and alien species interact to affect pollination. Biol Rev 85:777-795

Steffan-Dewenter I, Tscharntke T (2000) Butterfly community structure in fragmented habitats. Ecol Lett 3(5):449-456

Supp SR, Ernest SKM (2014) Species-level and communitylevel responses to disturbance: a cross-community analysis. Ecology 95:1717-1723
Thomas JA (1991) Rare species conservation: case studies of European butterflies. The scientific management of temperate communities for conservation: the 31st Symposium of the British Ecological Society Southampton 1989, pp. 149-197

Thomas JA (2016) Butterfly communities under threat. Science 353(6296):216-218

Tscharntke T, Tylianakis JM, Rand TA, Didham RK, Fahrig L, Batary P, Bengtsson J, Clough Y, Crist TO, Dormann CF, Ewers RM (2012) Landscape moderation of biodiversity patterns and processes-eight hypotheses. Biol Rev 87:661-685

Van Swaay CAM (2002) The importance of calcareous grasslands for butterflies in Europe. Biol Conserv 104:315-318

van Swaay CAM, WallisDeVries MF, Poschlod P (2002) Challenges for the conservation of calcareous grasslands in northwestern Europe: integrating the requirements of flora and fauna. Biol Conserv 104:265-273

Venables WN, Ripley BD (2002) Modern Applied Statistics with S. Springer, New York

Warren MS, Hill JK, Thomas JA, Asher J, Fox R, Huntley B, Jeffcoate G, Harding P, Willis SG, Greatorex-Davies JN, Moss D, Thomas CD (2001) Rapid responses of British butterflies to opposing forces of climate and habitat change. Nature 414(6859):65

Zulka KP, Abensperg-Traun M, Milasowszky N, Bieringer G, Gereben-Krenn B-A, Holzinger W, Hölzler G, Rabitsch W, Reischütz A, Querner P, Sauberer N, Schmitzberger I, Willner W, Wrbka T, Zechmeister H (2013) Species richness in dry grassland patches of eastern Austria: A multitaxon study on the role of local, landscape and habitat quality variables. Agric Ecosyst Environ 182:25-36

Publisher's Note Springer Nature remains neutral with regard to jurisdictional claims in published maps and institutional affiliations. 